\title{
$\mathrm{Sb} / \mathrm{Bi}$ 비가 $\mathrm{ZnO}-\mathrm{Bi}_{2} \mathrm{O}_{3}-\mathrm{Sb}_{2} \mathrm{O}_{3}-\mathrm{Mn}_{3} \mathrm{O}_{4}-\mathrm{Co}_{3} \mathrm{O}_{4}$ 바리스터의 소결과 입계 특성에 미치는 영향
}

\author{
홍연우 ${ }^{1, a}$, 이영진 ${ }^{1}$, 김세기 $^{1}$, 김진호 $^{2}$ \\ 1 한국세라믹기술원 기능성모듈팀 \\ 2 경북대학교 신소재공학부
}

\section{Effect of Sb/Bi Ratio on Sintering and Grain Boundary Properties of $\mathrm{ZnO}-\mathrm{Bi}_{2} \mathrm{O}_{3}-\mathrm{Sb}_{2} \mathrm{O}_{3}-\mathrm{Mn}_{3} \mathrm{O}_{4}-\mathrm{Co}_{3} \mathrm{O}_{4}$ Varistor}

\author{
Youn-Woo Hong ${ }^{1, \mathrm{a}}$, Young-Jin Lee ${ }^{1}$, Sei-Ki Kim ${ }^{1}$, and Jin-Ho Kim ${ }^{2}$ \\ ${ }^{1}$ Functional Module Team, Korea Institute of Ceramic Engineering and Technology, \\ Seoul 153-801, Korea \\ ${ }^{2}$ School of Materials Science and Engineering, Kyungpook National University, Daegu 702-701, Korea
}

(Received September 28, 2012; Revised October 22, 2012; Accepted October 23, 2012)

\begin{abstract}
In this study we aims to examine the co-doping effects of $1 / 3$ mol\% $\mathrm{Mn}_{3} \mathrm{O}_{4}+\mathrm{Co}_{3} \mathrm{O}_{4}$ (1:1) on the reaction, microstructure, and electrical properties such as the bulk defects and grain boundary properties of $\mathrm{ZnO}-\mathrm{Bi}_{2} \mathrm{O}_{3}-\mathrm{Sb}_{2} \mathrm{O}_{3}$ (ZBS; $\mathrm{Sb} / \mathrm{Bi}=0.5,1.0$, and 2.0) varistors. The sintering and electrical properties of $\mathrm{Mn}, \mathrm{Co}-$ doped $\mathrm{ZBS}$, ZBS(MCo) varistors were controlled by $\mathrm{Sb} / \mathrm{Bi}$ ratio. Pyrochlore $\left(\mathrm{Zn}_{2} \mathrm{Bi}_{3} \mathrm{Sb}_{3} \mathrm{O}_{14}\right)$ was decomposed and promoted densification at lower temperature on heating in $\mathrm{Sb} / \mathrm{Bi}=1.0$ by $\mathrm{Mn}$ rather than Co. Pyrochlore on cooling was reproduced in all systems however, spinel ( $a^{-}$or $\beta$-polymorph) did not formed in $\mathrm{Sb} / \mathrm{Bi}=0.5$. More homogeneous microstructure was obtained in $\mathrm{Sb} / \mathrm{Bi} \geq 1$.0. In $\mathrm{ZBS}(\mathrm{MCo})$, the varistor characteristics were improved drastically (non-linear coefficient, $a=30 \sim 49$ ), and seemed to form $Z n_{i}^{*}(0.17 \mathrm{eV})$ and $V_{o}^{*}(0.33 \mathrm{eV})$ as dominant defects. From impedance and modulus spectroscopy (IS \& $M S$ ), the grain boundaries have divided into two types, i.e. the one is tentatively assign to $\mathrm{ZnO} / \mathrm{Bi}_{2} \mathrm{O}_{3}(\mathrm{Mn}, \mathrm{Co}) / \mathrm{ZnO}(0.47 \mathrm{eV})$ and the other $\mathrm{ZnO} / \mathrm{ZnO}(0.80 \sim 0.89 \mathrm{eV})$ homojunctions.
\end{abstract}

Keywords: $\mathrm{ZnO}$ varistor, $\mathrm{Mn}_{3} \mathrm{O}_{4}, \mathrm{Co}_{3} \mathrm{O}_{4}$, Sintering, Electrical properties

\section{1. 서 론}

$\mathrm{ZnO}$ 바리스터에서 액상 소결 첨가제인 $\mathrm{Bi}_{2} \mathrm{O}_{3}$ 를 사 용한 계는 $\mathrm{ZnO}$ 의 입성장을 제어할 수 있는 $\mathrm{Sb}_{2} \mathrm{O}_{3}$ 를 대부분 포함하고 있으며, $\mathrm{Sb} / \mathrm{Bi}$ 비가 계의 상발달, 치 밀화, 미세구조 및 전기적 특성을 크게 좌우한다

a. Corresponding author; hyw-kea@kicet.re.kr
[1-8]. 기본계인 $\mathrm{ZBS}\left(\mathrm{ZnO}-\mathrm{Bi}_{2} \mathrm{O}_{3}-\mathrm{Sb}_{2} \mathrm{O}_{3}\right)$ 계에 첨가하 는 소량의 첨가물들 $(\mathrm{Mn}, \mathrm{Co}, \mathrm{Cr}, \mathrm{Ni}, \mathrm{Si}$ 등)은 2 차상 인 파이로클로어 $\left(\mathrm{Zn}_{2} \mathrm{Bi}_{3} \mathrm{Sb}_{3} \mathrm{O}_{14}\right)$ 의 생성과 분해반응 온도를 변화시키고 스피넬 $\left(\mathrm{Zn}_{7} \mathrm{Sb}_{2} \mathrm{O}_{12}\right)$ 의 생성에 영향 을 주어 미세구조를 제어할 뿐 아니라 바리스터 특성 을 제어한다 [5-8]. ZBS계에서 파이로클로어는 가열 중 $700^{\circ} \mathrm{C}$ 부근에서 생성되어 $2 \mathrm{Zn}_{2} \mathrm{Bi}_{3} \mathrm{Sb}_{3} \mathrm{O}_{14}(\mathrm{Py})+$ $17 \mathrm{ZnO} \rightleftharpoons 3 \mathrm{Zn}_{7} \mathrm{Sb}_{2} \mathrm{O}_{12}(\mathrm{Bsp})+3 \mathrm{Bi}_{2} \mathrm{O}_{3}$ (liq.)의 반응으로 
약 $950 \sim 1,050^{\circ} \mathrm{C}$ 에서 $\beta$-스피넬과 $\mathrm{Bi}$-rich 액상으로 분해하여 계의 치밀화를 촉진시킬 뿐 아니라 냉각 시 그 역반응에 의해 재합성된다 [5,7]. 이러한 반응은 다양한 첨가제에 의해 변하며 그 분해 온도와 재합성 여부도 달라진다 [5-7]. 또한 $\mathrm{ZnO}$ 바리스터의 특성을 개선할 목적으로 첨가하는 다양한 천이금속 산화물은 파이로클로어나 스피넬의 구성원소로도 작용하여 이 상들의 열역학적 특성에 영향을 줄 뿐 아니라 바리스 터 특성에도 영향을 준다 [5,9-11]. 첨가제 중 $\mathrm{Mn}$ 과 $\mathrm{Co}$ 는 모두 계면 상태 준위를 형성하여 바리스터의 비선형 계수를 높인다 [1-4]. $\mathrm{Mn}$ 은 $\mathrm{a}$-스피넬을 안정 화시켜 보다 균일한 미세구조를 형성하게 하고, 0.5 $\mathrm{mol} \%$ 이상 첨가 시 비선형 계수를 크게 높여준다 [1,2,5,7]. Co는 $0.1 \mathrm{~mol} \%$ 이상 첨가 시 비선형 계수 를 20 이상으로 높여주며, 그 함량이 $1 \mathrm{~mol} \%$ 이상일 경우 $\mathrm{ZnO}$ 의 비저항을 높여 고전류 영역 (반전 영역, up-turn region)의 비선형성을 떨어뜨리는 원인으로 작용한다 [2,12]. $\mathrm{ZnO}$ 바리스터에서 나타나는 주된 결 함으로는 $Z n_{i}$ 와 $V_{o}$ 이 확인되며, 또한 $\mathrm{ZnO}$ 바리스터에 서 확인되는 계면 상태 준위는 크게 두 부류로 구분할 수 있다 [1-4,8,13]. 이들은 $\mathrm{ZnO} / \mathrm{ZnO}$ 의 동종접합 계면과 $\mathrm{ZnO} / \mathrm{Bi}-$ rich상 $/ \mathrm{ZnO}$ 의 이종접합 계면으로서, 전자는 전류-전압의 비선형성을 나타내고, 후자는 누설 전류 와 관련된다 $[3,8,13]$. 복잡한 미세구조를 갖는 ZBS계 바리스터의 입내 및 입계 특성은 다양한 유전 함수 (dielectric functions: $Z^{*}, Y^{*}, M^{*}, \varepsilon^{*}, \tan \delta$ )를 함께 사 용하여 측정 주파수 대역과 온도 범위에 따라 종합적 으로 분석할 수 있다 [8,13-17]. 그러나 $\mathrm{Mn}$ 과 $\mathrm{Co}$ 를 동시에 첨가한 계에 대한 소결과 결함 및 입계 특성 을 종합적으로 분석하여 발표한 내용은 부족한 편이 다. 따라서 본 연구에서는 $\mathrm{ZBS}$ 계에 $\mathrm{Sb} / \mathrm{Bi}$ 비를 다르 게 한 후 $\mathrm{Mn}_{3} \mathrm{O}_{4}$ 와 $\mathrm{Co}_{3} \mathrm{O}_{4}$ 를 $1: 1$ 비율로 그 합이 $1 / 3$ $\mathrm{mol} \%$ 되도록 첨가한 5 성분 계에 대하여 소결과 전기 적 특성을 살펴봄으로써 $\mathrm{Mn}$ 과 $\mathrm{Co}$ 를 동시에 첨가함 에 따른 그 역할에 대하여 보다 상세하게 조사하였 다.

\section{2. 실험 방법}

본 연구에서는 순도 $99.9 \%$ (고순도 화학, 일본)의 $\mathrm{ZnO}, \mathrm{Bi}_{2} \mathrm{O}_{3}, \mathrm{Sb}_{2} \mathrm{O}_{3}, \mathrm{Mn}_{3} \mathrm{O}_{4}, \mathrm{Co}_{3} \mathrm{O}_{4}$ 를 사용하여 모상인 $\mathrm{ZnO}$ 에 $\mathrm{Sb} / \mathrm{Bi}=2.0$ (1.0 mol\% $\mathrm{Bi}_{2} \mathrm{O}_{3}, 2.0 \mathrm{~mol} \% \mathrm{Sb}_{2} \mathrm{O}_{3}$, $\left.1 / 6 \mathrm{~mol} \% \quad \mathrm{Mn}_{3} \mathrm{O}_{4}, 1 / 6 \quad \mathrm{~mol} \% \quad \mathrm{Co}_{3} \mathrm{O}_{4}\right), \mathrm{Sb} / \mathrm{Bi}=1.0(1.5$ $\mathrm{mol} \% \mathrm{Bi}_{2} \mathrm{O}_{3}, 1.5 \mathrm{~mol} \% \mathrm{Sb}_{2} \mathrm{O}_{3}, 1 / 6 \mathrm{~mol} \% \mathrm{Mn}_{3} \mathrm{O}_{4}, 1 / 6$ $\left.\mathrm{mol} \% \mathrm{Co}_{3} \mathrm{O}_{4}\right), \mathrm{Sb} / \mathrm{Bi}=0.5\left(2.0 \mathrm{~mol} \% \mathrm{Bi}_{2} \mathrm{O}_{3}, 1.0 \mathrm{~mol} \%\right.$ $\left.\mathrm{Sb}_{2} \mathrm{O}_{3}, 1 / 6 \mathrm{~mol} \% \mathrm{Mn}_{3} \mathrm{O}_{4}, 1 / 6 \mathrm{~mol} \% \mathrm{Co}_{3} \mathrm{O}_{4}\right)$ 인 3 종류 의 $\mathrm{ZBS}(\mathrm{MCo})$ 조성을 제작하여 일반적인 세라믹 공 정으로 혼합하여 출발 원료로 사용하였다. 소결을 위 하여 성형체는 출발 원료를 $\Phi 11 \mathrm{~mm}$ 의 원통형 금형에 장입하여 먼저 $25 \mathrm{MPa}$ 로 1축 가압 성형한 후 98 $\mathrm{MPa}$ 로 정수압 처리하여 제조하였다. 성형 시편은 700 $\sim 1,300^{\circ} \mathrm{C}$ 에서 1 시간 공기 중에서 소결하였으며, 승온 시 $500^{\circ} \mathrm{C}$ 에서 $\mathrm{Sb}$ 의 산화를 위하여 1시간 유지하였으 며, 승온 및 냉각 속도는 $5^{\circ} \mathrm{C} / \mathrm{min}$.로 고정하였다. 소 결 시편은 약 $1.0 \mathrm{~mm}$ 두께로 제작한 후 양면에 $\mathrm{Ag}$ 전극 (ohmic contact용)을 직경이 $\Phi 6 \mathrm{~mm}$ 가 되게 실 크 스크린으로 도포하여 소성로에 넣고 $600^{\circ} \mathrm{C}$ 에서 10 분 열처리하여 전기적 특성 측정용 시편으로 준비하 였다.

각 조성의 소결 상변화를 관찰하기 위하여 $\mathrm{X}$-선 회절 분석기 (M03X-HF, MAC Science Co. Ltd., Japan)로 분석하였으며, 밀도는 Archimedes법으로 구 하였다. 또한 소결 시편의 미세구조는 $0.4 \%$ 염산 수 용액으로 화학 에칭하여 SEM (S-4200, Hitachi, Japan)으로 관찰하였으며, 대략적인 상의 분포를 살 펴보기 위하여 BEI (backscattered electron image: RBH-4200 5MC, Robinson, Australia)로 관찰하였다.

전류-전압 $(I-V)$ 특성은 high voltage source meter (Keithley, 237, USA)를 사용하였으며, 바리스터의 비 선형 계수 $(a)$ 는 $I-V$ 측정값에 시편의 전극 단면적과 두께를 대입한 전류밀도-전기장 $(J-E)$ 곡선으로부터 $J=C E^{a}, \quad a=\log \left(J_{2} / J_{1}\right) / \log \left(E_{2} / E_{1}\right)$ 에 따라 구하였다. 여 기서 $J_{1}=1\left(\mathrm{~mA} / \mathrm{cm}^{2}\right), J_{2}=10\left(\mathrm{~mA} / \mathrm{cm}^{2}\right)$ 이며, $E_{1}$ 과 $E_{2}$ 는 각각 $J_{1}$ 과 $J_{2}$ 에서의 전장의 세기 $(\mathrm{V} / \mathrm{cm})$ 이다. 입계 당 항복전압 $\left(V_{g b}\right)$ 은 항복 전압 $\left(V_{b}, 1 \mathrm{~mA} / \mathrm{cm}^{2}\right.$ 에서의 전압), 시편의 두께 $(t), \mathrm{ZnO}$ 입자의 평균 입경 $(\bar{d})$ 으로 부터 $V_{g b}=V_{b} \cdot \bar{d} / t$ 로 구하였다. 누설 전류 밀도(leakage current density: $\left.J_{L}\right)$ 는 $0.8 V_{b}$ 에서의 전류 밀도 값으로 정하였다. 또한 pre-breakdown 영역의 $J-E$ 곡선의 기울기로부터 상온 비저항, $\rho \mathrm{gb}(\Omega \mathrm{cm})$ 를 구하였다.

결함과 입계 특성을 살펴보기 위한 impedance and modulus spectroscopy ( $I S \& M S$ )는 Impedance/gain phase analyzer (Hewlett Packard, 4194A, Japan)를 사 용하여 주파수는 $100 \mathrm{~Hz} \sim 15 \mathrm{MHz}$ 대역에서, 100 $720 \mathrm{~K}$ 까지 $20 \mathrm{~K}$ 간격으로 승온하면서 측정하였다. 각 유전 함수 별로 주파수 응답도 (frequency explicit plot)를 이용하여 각 피크의 최댓값에 대한 피크 온도 
$T_{p}$ 와 피크 주파수 $f_{\max }$ 를 구하고, 임피던스와 모듈러 스에서 각 허수부의 최댓값 $Z^{\prime \prime} \max ^{\prime}$ 와 $M^{\prime \prime} \max ^{2}$ 를 그래프 상에서 구하여 식 (2)를 이용하여 입계 저항 $\left(R_{g b}\right)$ 과 정전용량 $\left(C_{g b}\right)$ 을 추출하였다 [13].

$$
Z_{\max }^{\prime \prime}=\frac{R}{2}, \quad M_{\max }^{\prime \prime}=\frac{C_{0}}{2 C}
$$

이렇게 구한 $T_{p}$ 와 $\tau^{-1}=\omega_{\max }=2 \pi f_{\max }, Z^{\prime \prime}$ max,$M^{\prime \prime}{ }_{\max }$ 는 아 레니우스(Arrehnius)식 $\left(\tau=\tau_{0} \exp \left(E_{a} / k T\right), \rho=\rho_{0} \exp \left(E_{a} / k T\right)\right.$, $\tau$ 완화시간, $\rho=$ 비저항 $(\Omega \mathrm{cm}), E_{a}=\tau$ 혹은 $\rho$ 에 대한 활 성화 에너지, $k=$ 볼쯔만 상수 $\left(8.62 \times 10^{-5}(\mathrm{eV} / \mathrm{K})\right), T=$ 온 도 $(\mathrm{K}))$ 을 이용하여 각각 $\ln \tau$ vs. $1,000 / T$ 및 $\ln \rho$ vs, $1,000 / T$ 그래프를 통하여 그 기울기로부터 상온 이하 의 값에서는 결함 준위 (혹은 이온화 에너지, $E_{b t}$ ) 와 상온 이상에서는 입계 활성화 에너지 $\left(E_{a}\right)$ 를 구하는데 사용하였다 [13].

\section{3. 결과 및 고찰}

\subsection{XRD 분석}

그림 1 은 $\mathrm{Sb} / \mathrm{Bi}$ 비를 달리한 $\mathrm{ZBS}(\mathrm{MCo})$ 계( $(\mathrm{a})$ $\mathrm{Sb} / \mathrm{Bi}=2.0$, (b) $\mathrm{Sb} / \mathrm{Bi}=0.5)$ ) 시편을 $700 \sim 1,300^{\circ} \mathrm{C}$ 로 소 결한 후 서냉하였을 때 나타나는 XRD 패턴이다. 표 1 은 $\mathrm{Sb} / \mathrm{Bi}$ 비 $(2.0,1.0,0.5)$ 를 달리한 $\mathrm{ZBS}(\mathrm{MCo})$ 계 전 체에 대한 2 차상의 변화를 정리한 것이다.

그림 1 과 같이 $\mathrm{Sb} / \mathrm{Bi}=2.0$ 에서는 파이로클로어 $\left(\mathrm{Zn}_{2} \mathrm{Sb}_{3} \mathrm{Bi}_{3} \mathrm{O}_{14}\right)$ 와 $\mathrm{a}$-스피넬 $\left(\mathrm{Zn}_{7} \mathrm{Sb}_{2} \mathrm{O}_{12}\right)$ 및 극미량의 $\beta-\mathrm{Bi}_{2} \mathrm{O}_{3}$ 가 나타나며, $\mathrm{Sb} / \mathrm{Bi}=0.5$ 에서는 파이로클로어, $\beta-\mathrm{Bi}_{2} \mathrm{O}_{3}$ 와 $\gamma-\mathrm{Bi}_{2} \mathrm{O}_{3}$ 가 생성되었다 (표 1 참고). 표 1 에 서 보듯이 $\mathrm{Sb} / \mathrm{Bi}$ 비에 따라 2 차상의 종류가 다르게 나 타났다. 다만 $\mathrm{Sb} / \mathrm{Bi}$ 비와 관계없이 모든 계에서 파이 로클로어가 냉각 중 재생성되었으며, 잔류 $\mathrm{Bi}$-rich 상 은 $\beta-\mathrm{Bi}_{2} \mathrm{O}_{3}$ 로 존재하였다. $\mathrm{Sb} / \mathrm{Bi} \geq 1.0$ 은 소결온도에 따라 그 구성상이 동일하였지만, $\mathrm{Sb} / \mathrm{Bi}=0.5$ 는 특별히 $a^{-}$스피넬이 생성되지 않았다. 이 $a^{-}$스피넬은 $\mathrm{ZnO}$ 바 리스터에서 입성장을 제어하여 보다 균일한 미세구조 를 형성하는 상이지만, $\beta$-스피넬은 오히려 막대형의 불균일한 미세구조를 형성하는 상으로 알려져 있기 때문에 $\mathrm{Sb} / \mathrm{Bi}=0.5$ 인 계는 다소 불균일한 미세구조를 형성할 것으로 판단된다 [7,18-20]. $\mathrm{ZBS}$ 계는 $\mathrm{Sb} / \mathrm{Bi}$ 비 와 관계없이 $\beta$-스피넬을 형성하고, 여기에 $\mathrm{Mn}$ 이나
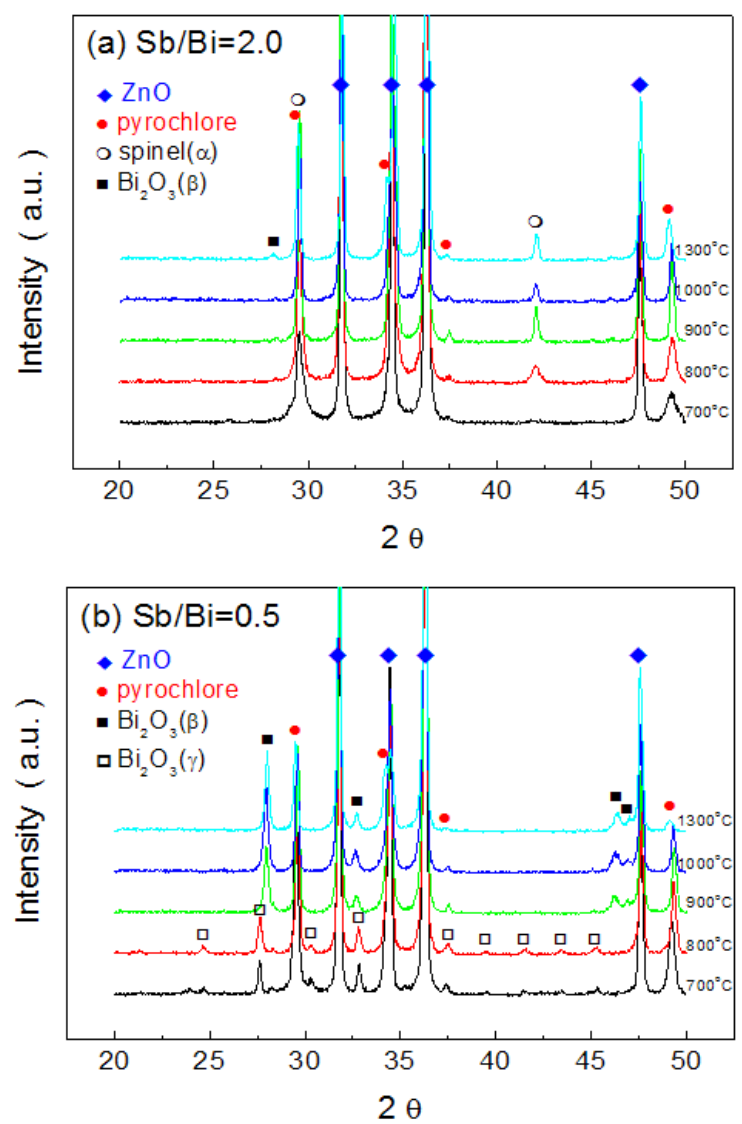

Fig. 1. XRD patterns of $\mathrm{ZBS}(\mathrm{MCo}$ ) system (a) $\mathrm{Sb} / \mathrm{Bi}=2.0$ and (b) $\mathrm{Sb} / \mathrm{Bi}=0.5$ with sintering temperatures.

Table 1. Secondary phases in $\mathrm{ZBS}(\mathrm{MCo})(\mathrm{Sb} / \mathrm{Bi}=2.0,1.0$, and 0.5$)$ sintered at various temperatures. (Py: $\mathrm{Zn}_{2} \mathrm{Sb}_{3} \mathrm{Bi}_{3} \mathrm{O}_{14}, \quad$ asp: $\quad a-\mathrm{Zn}_{7} \mathrm{Sb}_{2} \mathrm{O}_{12}, \quad \beta: \quad \beta-\mathrm{Bi}_{2} \mathrm{O}_{3}, \quad \gamma: \quad \gamma-\mathrm{Bi}_{2} \mathrm{O}_{3}$, $(\beta)$ : trace of $\beta-\mathrm{Bi}_{2} \mathrm{O}_{3}$ ).

\begin{tabular}{ccccc} 
Temp. & $700{ }^{\circ} \mathrm{C}$ & $800{ }^{\circ} \mathrm{C}$ & $900{ }^{\circ} \mathrm{C}$ & $1,000 \sim 1,300{ }^{\circ} \mathrm{C}$ \\
\hline $\mathrm{Sb} / \mathrm{Bi}$ & $\mathrm{Py}$ & $\mathrm{Py}+\mathrm{asp}$ & $\mathrm{Py}+\mathrm{asp}+(\beta)$ \\
\hline 2.0 & & & \\
\hline 1.0 & & $\mathrm{Py}+\beta$ \\
\hline 0.5 & $\mathrm{Py}+\gamma$ & \\
\hline
\end{tabular}

$\mathrm{Cr}$ 을 첨가 시 전체적으로 $\mathrm{a}$-스피넬을 형성하는 것과 는 차이가 나는 현상이다 [7,20]. 반면, $\mathrm{Co}$ 혹은 $\mathrm{Ni}$ 를 첨가한 $Z \mathrm{BS}$ 계의 경우, $\mathrm{Sb} / \mathrm{Bi} \geq 1.0$ 에서 모두 $\beta$-스피 넬을 형성하고, $\mathrm{Sb} / \mathrm{Bi}=0.5$ 에서 $\mathrm{Co}$ 첨가는 어떤 스피 넬도 형성하지 않지만, $\mathrm{Ni}$ 첨가로 $\mathrm{a}-$ 스피넬을 형성하 는 것과도 차이가 나는 현상이다 $[18,19]$. 특별히 $\mathrm{Ni}$ 를 첨가한 $\mathrm{ZBS}$ 계가 $1,000^{\circ} \mathrm{C}$ 이상의 소결온도에서 
$\mathrm{Sb} / \mathrm{Bi}$ 비와 관계없이 파이로클로어를 형성하지 않는 것과도 비교된다 [19]. 뿐만 아니라 $\mathrm{Bi}$-rich 상의 경 우, 본 조성계는 단순 $\mathrm{ZBS}$ 와 여기에 $\mathrm{Mn}$ 이나 $\mathrm{Co}$ 혹 은 $\mathrm{Ni}$ 를 첨가한 조성계와 같은 $\beta-\mathrm{Bi}_{2} \mathrm{O}_{3}$ 를 형성하지 만, $\mathrm{Cr}$ 을 첨가할 때 $\delta-\mathrm{Bi}_{2} \mathrm{O}_{3}$ 를 형성하는 것과도 차이 가 난다 [7,18-20]. 요약하면, $\mathrm{Mn}$ 과 $\mathrm{Cr}$ 은 $\mathrm{a}$-스피 넬의 생성과 안정화를 도모하는 역할을 하는 반면, $\mathrm{Co}$ 와 $\mathrm{Ni}$ 는 그렇지 않다. 본 조성계와 같이 $\mathrm{Mn}$ 과 $\mathrm{Co}$ 를 함 께 첨가할 경우, $\mathrm{Sb} / \mathrm{Bi} \geq 1.0$ 일 때 $\mathrm{Mn}$ 이 주도적인 역 할을 하지만, $\mathrm{Sb} / \mathrm{Bi}=0.5$ 인 경우 $\mathrm{Co}$ 가 주도적인 역할 을 하는 것으로 결론내릴 수 있겠다.

따라서 상발달과 관련하여 $\mathrm{ZBS}$ 에 $\mathrm{Mn}$ 과 $\mathrm{Co}$ 를 동 시에 첨가할 경우, $\mathrm{Sb} / \mathrm{Bi}$ 비와 관계없이 파이로클로어 가 냉각 시 재생성 되었으며, $\mathrm{Bi}-\mathrm{rich}$ 상은 $\mathrm{\beta}-\mathrm{Bi}_{2} \mathrm{O}_{3}$ 로 존재하였고, $a-$ 스피넬은 $\mathrm{Sb} / \mathrm{Bi} \geq 1.0$ 에서 생성되지만, $\mathrm{Sb} / \mathrm{Bi}=0.5$ 에서는 생성되지 않았다. 즉, $\mathrm{Mn}$ 은 $\mathrm{Sb} / \mathrm{Bi}$ $\geq 1.0$ 에서 $\mathrm{a}^{-}$스피넬의 생성과 안정화에 주도적 역할 을 하고, $\mathrm{Co}$ 는 $\mathrm{Sb} / \mathrm{Bi}=0.5$ 에서 스피넬 생성을 억제하 는 역할을 하였다. 결국, 각 첨가제의 종류에 따라 상 발달의 차이로 말미암아 계의 치밀화 거동이 사뭇 달 라질 것이라 예상할 수 있다.

\section{2 밀도 변화}

그림 2 는 $\mathrm{Sb} / \mathrm{Bi}$ 비에 따른 $\mathrm{ZBS}(\mathrm{MCo})$ 계의 소결 온 도별 상대 밀도를 계산한 것이다.

$1,000^{\circ} \mathrm{C}$ 이상에서 $\mathrm{Sb} / \mathrm{Bi}$ 비와 관계없이 일반적으로 알려진 소결 중 $\mathrm{Bi}-$ rich 액상의 휘발에 의한 상대밀 도의 감소가 확인되었으며, 그 감소폭은 $\mathrm{Sb} / \mathrm{Bi}$ 비가 낮아질수록 커지는 경향으로 나타났다. 반면 700 $1,000^{\circ} \mathrm{C}$ 구간에서는 $\mathrm{Sb} / \mathrm{Bi}$ 비에 따라 상당한 차이를 보이고 있다. 먼저 $\mathrm{Sb} / \mathrm{Bi}=2.0$ 는 그림 1 과 표 1 에서 보듯이 $700^{\circ} \mathrm{C}$ 에서 생성된 파이로클로어 (Py, $d=7.86$ $\mathrm{g} / \mathrm{cm}^{3}$ )와 $800^{\circ} \mathrm{C}$ 에서 생성된 스피넬 ( $\mathrm{asp}, d=6.25$ $\mathrm{g} / \mathrm{cm}^{3}$ )로 말미암아 $900^{\circ} \mathrm{C}$ 까지 치밀화가 억제 (상대밀 도 $\sim 60 \%)$ 되고, $1,000^{\circ} \mathrm{C}$ 에서 파이로클로어의 분해로 생성된 $\mathrm{Bi}-$ rich 액상 $\left(\beta-\mathrm{Bi}_{2} \mathrm{O}_{3}, d=9.17 \mathrm{~g} / \mathrm{cm}^{3}\right)$ 에 의 해 치밀화가 촉진됨에 따라 상대밀도는 $~ 97 \%$ 로 높 아졌다. $\mathrm{Sb} / \mathrm{Bi}=1.0$ 은 $\mathrm{Sb} / \mathrm{Bi}=2.0$ 과 비슷하지만 $900^{\circ} \mathrm{C}$ 에 서 치밀화가 약간 진행되어 상대밀도가 약 $75 \%$ 에 도 달하였다. 이는 $900^{\circ} \mathrm{C}$ 에서 $\mathrm{ZBS}(\mathrm{Sb} / \mathrm{Bi}=1.0)$ 계의 $59 \%$ 와 여기에 $\mathrm{Co}$ 를 첨가한 $\mathrm{ZBSCo}(\mathrm{Sb} / \mathrm{Bi}=1.0)$ 의 $63 \%$ 보 다 높지만, $\mathrm{Cr}$ 이나 $\mathrm{Ni}$ 혹은 $\mathrm{Mn}$ 을 첨가한 계 $(\mathrm{ZBSCr}$ : $80 \%, \mathrm{ZBSN}: 88 \%, \mathrm{ZBSM}: 89 \%$ ) 보다 낮은 값이다

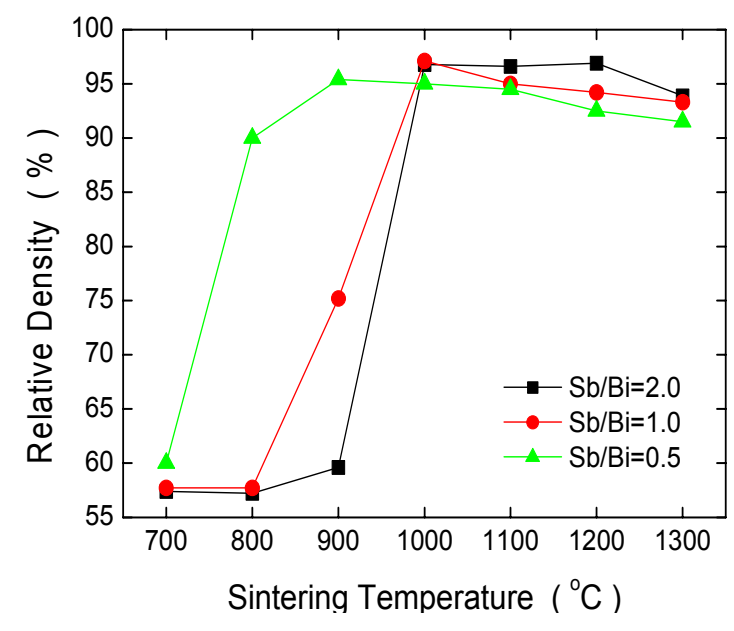

Fig. 2. Relative density of $\mathrm{ZBS}(\mathrm{MCo}) \quad(\mathrm{Sb} / \mathrm{Bi}=2.0,1.0$, and 0.5 ) sintered at various temperatures.

\section{[7,18-20].}

따라서 $\mathrm{Mn}$ 과 $\mathrm{Co}$ 를 동시에 첨가할 경우, $\mathrm{Co}$ 와 $\mathrm{Mn}$ 은 모두 파이로클로어의 구성 원소로 작용하지만, $\mathrm{Co}$ 보다 $\mathrm{Mn}$ 이 보다 낮은 온도에서 파이로클로어의 분해 를 촉진시킴에 따라 $\mathrm{Sb} / \mathrm{Bi}=1.0$ 의 치밀화가 촉진됨을 알 수 있다 $[7,9,18] . \mathrm{Sb} / \mathrm{Bi}=0.5$ 는 $800^{\circ} \mathrm{C}$ 에서 $90 \%$ 의 높은 상대밀도를 보이는데 이는 일반적으로 ZBS계와 여기에 $\mathrm{Mn}, \mathrm{Co}, \mathrm{Ni}$ 등을 첨가한 계에서 파이로클로 어 생성에 참여하지 않은 잔류 $\mathrm{Bi}_{2} \mathrm{O}_{3}$ 에 의해 상대적 으로 높은 상대밀도를 나타내는 현상과 동일한 거동 이며, $800^{\circ} \mathrm{C}$ 에서 미지의 상에 의한 치밀화의 억제로 $65 \%$ 의 낮은 상대밀도를 나타내는 $\mathrm{Cr}$ 첨가 효과와는 차이를 보인다 [7,18-20].

따라서 $\mathrm{ZBS}$ 계에 $\mathrm{Mn}$ 과 $\mathrm{Co}$ 를 동시에 첨가할 경우, 그 밀도 변화는 $\mathrm{Sb} / \mathrm{Bi}$ 비에 의해 달라졌으며, $\mathrm{Co}$ 보다 $\mathrm{Mn}$ 의 역할이 상대적으로 크게 나타났다.

\section{3 미세구조}

그림 3 은 $\mathrm{ZBS}(\mathrm{MCo})(\mathrm{Sb} / \mathrm{Bi}=2.0,1.0,0.5)$ 계를 1,00 $0{ }^{\circ} \mathrm{C}$ 에서 1 시간 소결한 시편의 미세구조를 나타낸 것 이다. $\mathrm{ZnO}$ 결정립은 상대적으로 짙은 회색, $\mathrm{Bi}-\mathrm{rich}$ 상은 흰색, 파이로클로어와 $\mathrm{a}$-스피넬는 모두 $\mathrm{ZnO}$ 보 다 옅은 회색으로 보이지만 그림 3(a)와 같이 파이로 클로어가 $a-$ 스피넬 보다 더 옅은 회색으로 구분된다 [7,18-20]. 

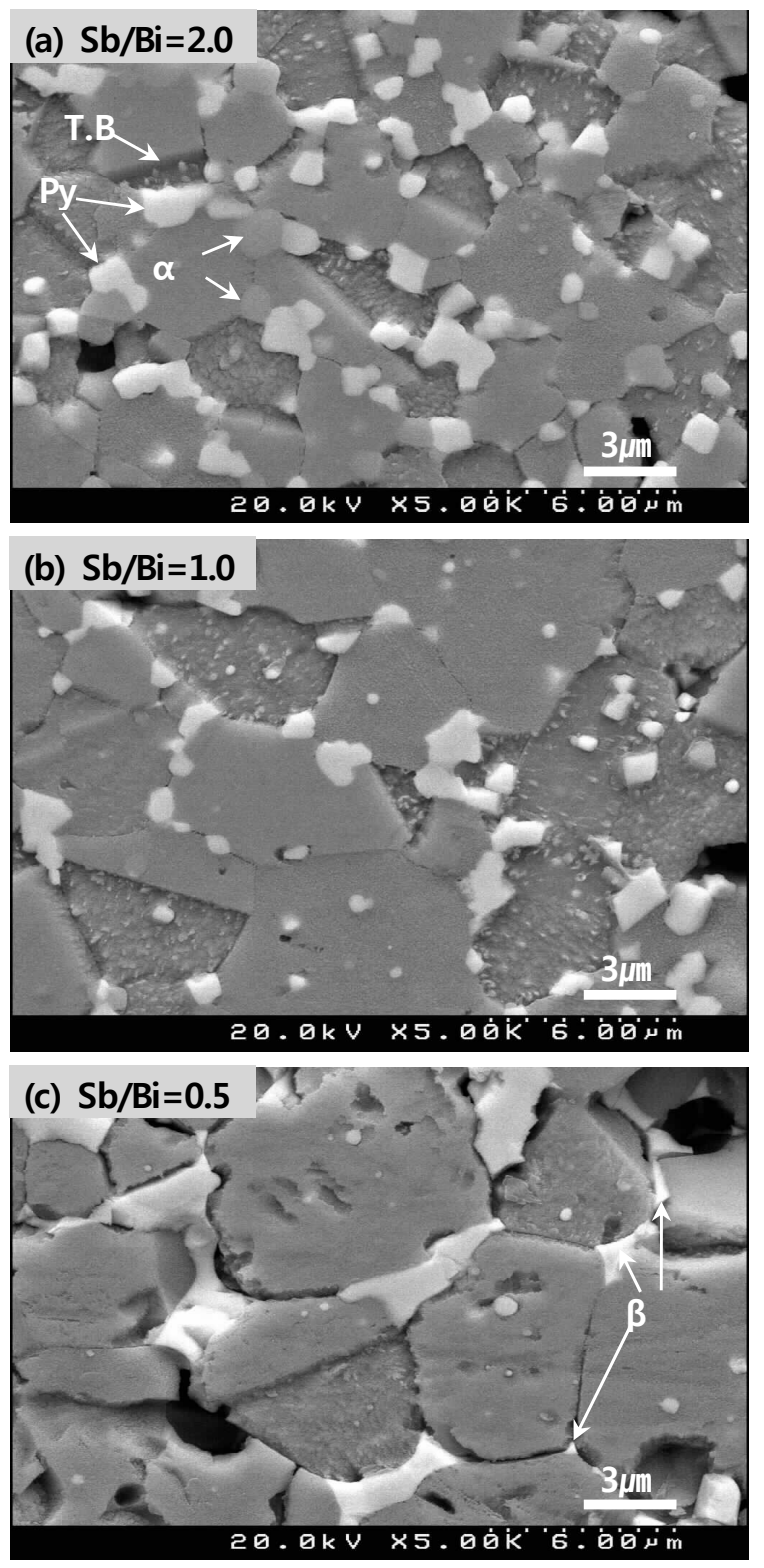

Fig. 3. Microstructure of $\mathrm{ZBS}(\mathrm{MCo})(\mathrm{Sb} / \mathrm{Bi}=2.0,1.0$, and 0.5) systems sintered at $1,000^{\circ} \mathrm{C}$ (T. B.: twin boundary).

그림 $3(\mathrm{a})$ 와 $(\mathrm{b})$ 에서 보듯이 $\mathrm{Sb} / \mathrm{Bi} \geq 1.0$ 인 시편의 미세구조는 동일한 2 차상 (그림 1 , 표 1 참고)으로 구 성되기 때문에 초기 치밀화가 우선적으로 진행된 $\mathrm{Sb} / \mathrm{Bi}=1.0$ 의 $\mathrm{ZnO}$ 평균입경이 크게 나타났다. 즉, 그 림 3 에서 선형 교차법으로 계산한 $\mathrm{ZnO}$ 의 평균입경은 각각 $3.1 \mu \mathrm{m}(\mathrm{Sb} / \mathrm{Bi}=2.0), 6.6 \mu \mathrm{m}(\mathrm{Sb} / \mathrm{Bi}=1.0), 11.0 \mu \mathrm{m}$ ( $\mathrm{Sb} / \mathrm{Bi}=0.5$ )이다. $\mathrm{Sb} / \mathrm{Bi} \geq 1.0$ 의 미세구조는 $\mathrm{a}$-스피넬 에 의한 미세구조 균일화 효과로 보다 균일한 미세구
조를 확보할 수 있는 것으로 확인된다. 이는 $\mathrm{Mn}$ 이나 $\mathrm{Cr}$ 혹은 $\mathrm{Ni}$ 를 첨가한 $\mathrm{ZBS}$ 계 중 $\mathrm{a}^{-}$스피넬로 구성된 계의 미세구조 균일화 효과와 일치한다 [7,19,20]. 그 림 3(c)와 같이 $\mathrm{Sb} / \mathrm{Bi}=0.5$ 의 미세구조는 뚜렷이 그 균 일성을 확인할 수 없지만, 계 내에 파이로클로어와 $\beta$ $-\mathrm{Bi}_{2} \mathrm{O}_{3}$ 만으로 구성되기 때문에 상대적으로 불균일한 미세구조를 갖게 될 것으로 판단된다 $[7,18]$.

따라서 $\mathrm{ZnO}$ 바리스터 조성을 개발하는 단계에서 $\mathrm{Mn}$ 과 $\mathrm{Co}$ 를 동시에 첨가제로 사용할 경우, $\mathrm{a}-$ 스피넬 을 형성하는 $\mathrm{Sb} / \mathrm{Bi} \geq 1.0$ 조성을 선택하는 것이 미세구 조의 균일화를 확보하는데 유리할 것으로 판단된다.

\section{$3.4 \mathrm{I}-\mathrm{V}$ 특성}

그림 4 는 $1,000^{\circ} \mathrm{C}$ 에서 소결한 시편의 $J-E$ 특성과 각 소결 온도 별 $J-E$ 곡선으로부터 계산한 비선형 계수(a) 를 $\mathrm{Sb} / \mathrm{Bi}$ 비에 따라 그래프로 나타낸 것이다. 또한 표 2 는 $1,000^{\circ} \mathrm{C}$ 에서 소결한 시편의 $J-E$ 특성을 요약한 것이다.
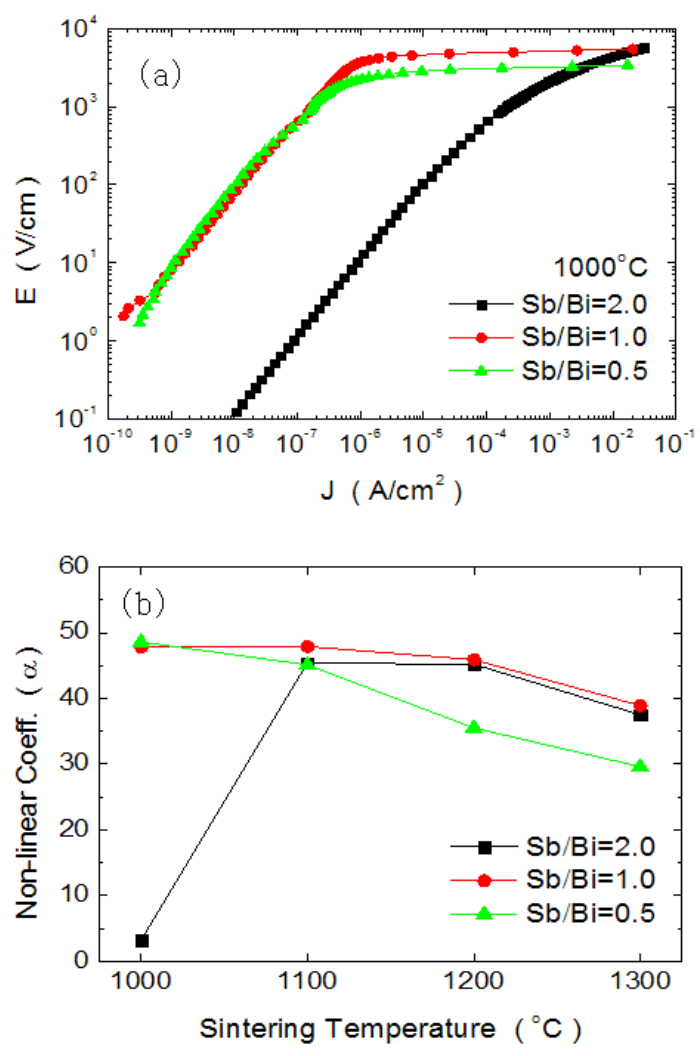

Fig. 4. (a) $J-E$ characteristics of $\mathrm{ZBS}(\mathrm{MCo})(\mathrm{Sb} / \mathrm{Bi}=2.0$, 1.0, and 0.5) sintered at $1,000^{\circ} \mathrm{C}$. (b) Non-linear coefficient $a$ with sintering temperature. 
Table 2. Summary of $J-E$ characteristics of ZBS(MCo) sintered at $1,000^{\circ} \mathrm{C}$.

\begin{tabular}{ccccc}
\hline $\begin{array}{r}\mathrm{Sb} / \mathrm{Bi} \\
\text { ratio }\end{array}$ & $a$ & $\begin{array}{c}V_{g b} \\
(\mathrm{~V})\end{array}$ & $\begin{array}{c}J_{L} \\
\left(\mu \mathrm{A} / \mathrm{cm}^{2}\right)\end{array}$ & $\begin{array}{c}\rho g b \\
(\Omega \mathrm{cm})\end{array}$ \\
\hline 2.0 & 3 & 0.7 & 577 & $1.2 \times 10^{7}$ \\
1.0 & 48 & 3.4 & 1.7 & $7.4 \times 10^{9}$ \\
0.5 & 49 & 3.5 & 2.6 & $1.0 \times 10^{10}$ \\
\hline
\end{tabular}

그림 $4(\mathrm{a})$ 와 표 2 에서 보듯이 $1,000^{\circ} \mathrm{C}$ 시편에서 $\mathrm{Sb} / \mathrm{Bi}=2.0$ 의 경우 바리스터 특성이 거의 나타나지 않 지만 $(\mathrm{a}=3), \mathrm{Sb} / \mathrm{Bi} \leq 1.0$ 의 경우 우수한 바리스터 특 성 ( $\left.\mathrm{a} \geq 48, V_{g b} \sim 3.4 \mathrm{~V}, J_{L}<3 \mu \mathrm{A} / \mathrm{cm}^{2}, \rho_{g b}>7 \mathrm{G} \Omega\right)$ 이 나 타났다 [18]. 특히 $\mathrm{Sb} / \mathrm{Bi}=2.0$ 은 $\mathrm{Sb} / \mathrm{Bi}=1.0$ 과 구성상 과 상대밀도 및 미세구조가 거의 동일하지만 바리스 터 특성이 나쁘게 나타나는데 이는 $1,000^{\circ} \mathrm{C}$ 에서 $\mathrm{Py}$ 의 분해에 의한 $\mathrm{Bi}$-rich 액상의 생성량이 극미량이고 또 한 냉각 시 충분히 $\mathrm{ZnO}$ 입계를 적시지 못하고 급히 $\mathrm{Py}$ 로 재합성 $\left(\sim 900^{\circ} \mathrm{C}\right)$ 되는 데 소모됨에 따라 입계에 서 이중 Schottky 장벽을 형성하여 바리스터 특성을 발현하게 하는 역할을 하지 못하기 때문으로 사료된 다 [1]. 그림 4(b)에서 보듯이 ZBS에 $\mathrm{Mn}$ 과 $\mathrm{Co}$ 를 동 시에 첨가할 경우 우수한 바리스터 특성을 확보할 수 있음을 알 수 있으며, 소결온도가 높아짐에 따라 $\mathrm{Sb} / \mathrm{Bi} \geq 1.0$ 의 비선형 계수는 소폭으로 감소하지만, $\mathrm{Sb} / \mathrm{Bi}=0.5$ 의 경우 49 에서 30 으로 상대적으로 다소 크 게 낮아지는 것을 볼 수 있다 (단, $1,000^{\circ} \mathrm{C} \mathrm{Sb} / \mathrm{Bi}=2.0$ 제외).

따라서 $\mathrm{Mn}$ 과 $\mathrm{Co}$ 를 동시에 첨가한 $\mathrm{ZBS}(\mathrm{MCo})$ 계는 $\mathrm{Sb} / \mathrm{Bi} \geq 1.0$ 일 때 상대적으로 균일하고 우수한 $J-E$ 특성을 확보할 수 있음을 알 수 있다 (단, $1,000^{\circ} \mathrm{C}$ $\mathrm{Sb} / \mathrm{Bi}=2.0$ 제외 $)$.

\subsection{IS \& MS 분석}

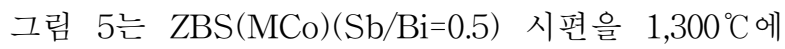
서 소결한 후 주파수와 온도에 따라 $I S \& M S$ 특성 을 측정한 것으로 (a) $160 \sim 240 \mathrm{~K}$ 영역에서의 $M^{\prime \prime}-\log f$ 를, (b) $Z^{\prime \prime}-\log f(480 \mathrm{~K})$ 와 $M^{\prime \prime}-\log f(480 \sim 600$ $\mathrm{K})$ 를, (c)는 $\ln \rho$ 와 $\ln \tau$ vs. $1,000 / T$ 를, (d)는 저항 ( $R_{1}$ $\left.{ }_{4}\right)$ 과 정전용량 $\left(C_{1 \sim 4}\right)$ 을 계산하여 도시한 것이다.

그림 5(a)와 같이 상온 이하의 온도에서 측정한 $M^{\prime \prime}-\log f$ 그래프는 특정 결함에 해당하는 $\mathrm{P} 1$ 과 $\mathrm{P} 2$ 가
확인되었고, 각 피크에 대하여 아레니우스 플롯하여 그 활성화 에너지 $\left(E_{b t}\right)$ 를 계산한 결과, $0.17 \mathrm{eV}(\mathrm{P} 1)$ 와 $0.33 \mathrm{eV}$ (P2)로 나타났는데(그림 5(c) 참고), 이는 주 결함이 각각 $Z n_{i}^{*}$ 와 $V_{o}^{*}$ 임을 알 수 있다 [1,4,8,18-21].

또한 $Z n_{i}^{*}$ 와 $V_{o}^{*}$ 에 의해 발현하는 저항과 정전용량 은 각각 $R_{1}$ 과 $C_{1}$ 및 $R_{2}$ 와 $C_{2}$ 로 그림 $5(\mathrm{~d})$ 와 같이 계 산되었다. 결함으로 인해 발현하는 저항은 온도에 따 라 지수적으로 감소하지만, 정전용량은 $C_{1}(2.4 \rightarrow 2.0$ $\mathrm{nF}$, 감소)과 $C_{2}(1.2 \sim 1.3 \mathrm{nF}$, 감소 후 증가)는 다소 다 른 거동을 나타냈다 $[18,20,21]$. 각 결함에 대한 등가 회로 해석에 대해서는 보다 깊이 있는 연구가 추후 진행되어야 할 것으로 사료된다.

그림 5(b)는 상온 이상의 온도에서 측정한 임피던 스와 모듈러스 피크 중 $Z^{\prime \prime}-\log f(480 \mathrm{~K})$ 와 $M^{\prime \prime}-\log f$ (480 600 K)의 입계 특성을 보여 주고 있다. 여기서 모듈러스의 $\mathrm{P} 3$ 과 $\mathrm{P} 4$, 임피던스의 $\mathrm{P}_{\mathrm{Z}}$ 에 해당하는 3 종 류의 피크를 볼 수 있는데, 결과적으로 본 조성계는 2 종류의 입계로 구성되어 있음을 알 수 있다 $[3,8,13,20,21]$. 각 피크에 대한 저항과 시정수에 대하 여 아레니우스 플롯을 통하여 각 입계의 활성화 에너 지를 계산한 결과, $\mathrm{P} 3$ 은 $0.47 \mathrm{eV}, \mathrm{P} 4$ 는 $0.89 \mathrm{eV}, \mathrm{Pz}$ 는 $0.80 \mathrm{eV}$ 를 가졌다 (그림 5(c) 참고). $480 \mathrm{~K}$ 에서 P3의 저항과 정전용량은 각각 $4.4 \mathrm{k} \Omega$ 과 $1.0 \mathrm{nF}$ 을, $\mathrm{P} 4$ 는 각 각 $0.3 \mathrm{M} \Omega$ 과 $1.0 \mathrm{nF}$ 으로 저항은 약 70 배의 차이를 보이지만 정전용량은 거의 동일한 값을 가지고 있다. 이는 일반적으로 알려진 $\mathrm{ZnO}$ 바리스터의 입계가 등 가 회로적으로 $R_{3} C_{3}$ (병렬)과 $R_{4} C_{4}$ (병렬)가 서로 직 렬로 연결된 것과 일치한다 $[3,8,13,20,21]$.

따라서 $\mathrm{P} 3$ 은 그림 $5(\mathrm{~b}, \mathrm{c}, \mathrm{d})$ 와 같이 온도에 대한 저항 $(R 3)$ 과 정전용량 $\left(C_{3}\right)$ 의 변화를 볼 때, 누설전류와 연관 되는 $\mathrm{ZnO} / \mathrm{Bi}_{2} \mathrm{O}_{3}(\mathrm{Mn}, \mathrm{Co}) / \mathrm{ZnO}$ 계면으로 볼 수 있으며, $\operatorname{ZBSM}(\mathrm{Sb} / \mathrm{Bi}=0.5)$ 에서 $\mathrm{Mn}$ 에 의해 발현하는 $0.4 \mathrm{eV}$ 의 입계와 동일하다고 할 수 있지만, 다만 $R_{3}$ 값이 ZBSM 계보다 10배 정도 더 높다 [21]. 반면, 본 조성계의 P3 입계의 활성화 에너지 $(0.47 \mathrm{eV})$ 는 이중 입계를 갖는 조성계 중 $\mathrm{ZBS}(\mathrm{Sb} / \mathrm{Bi}=0.5)$ 의 $1.02 \mathrm{eV}$, 상용 바리스터에 서 확인되는 $0.64 \mathrm{eV}, \mathrm{Ni}$ 를 첨가한 $Z \mathrm{BSN}(\mathrm{Sb} / \mathrm{Bi}=0.5)$ 의 $0.95 \mathrm{eV}, \mathrm{Cr}$ 을 첨가한 $\mathrm{ZBSCr}(\mathrm{Sb} / \mathrm{Bi}=0.5)$ 의 $0.95 \mathrm{eV}, \mathrm{Cr}$ 을 첨가한 $\mathrm{ZBCr}$ 계의 $1.2 \mathrm{eV}$ 보다 낮은 값을 가졌다 [8,13,19,20,22].

한편, $\mathrm{P} 4$ 는 $\mathrm{P} 3$ 과 비교하여 동일 온도에서 저항 $\left(R_{4}\right)$ 이 약 70 배 $(480 \mathrm{~K})$ 이상 높고, 정전용량 $\left(C_{4}\right)$ 이 거의 동일한 것을 볼 때 $\mathrm{ZnO} / \mathrm{ZnO}$ 입계로 볼 수 있 다 [3,8,13,21,22]. P4와 PZ에 해당하는 입계는 ZBSM 

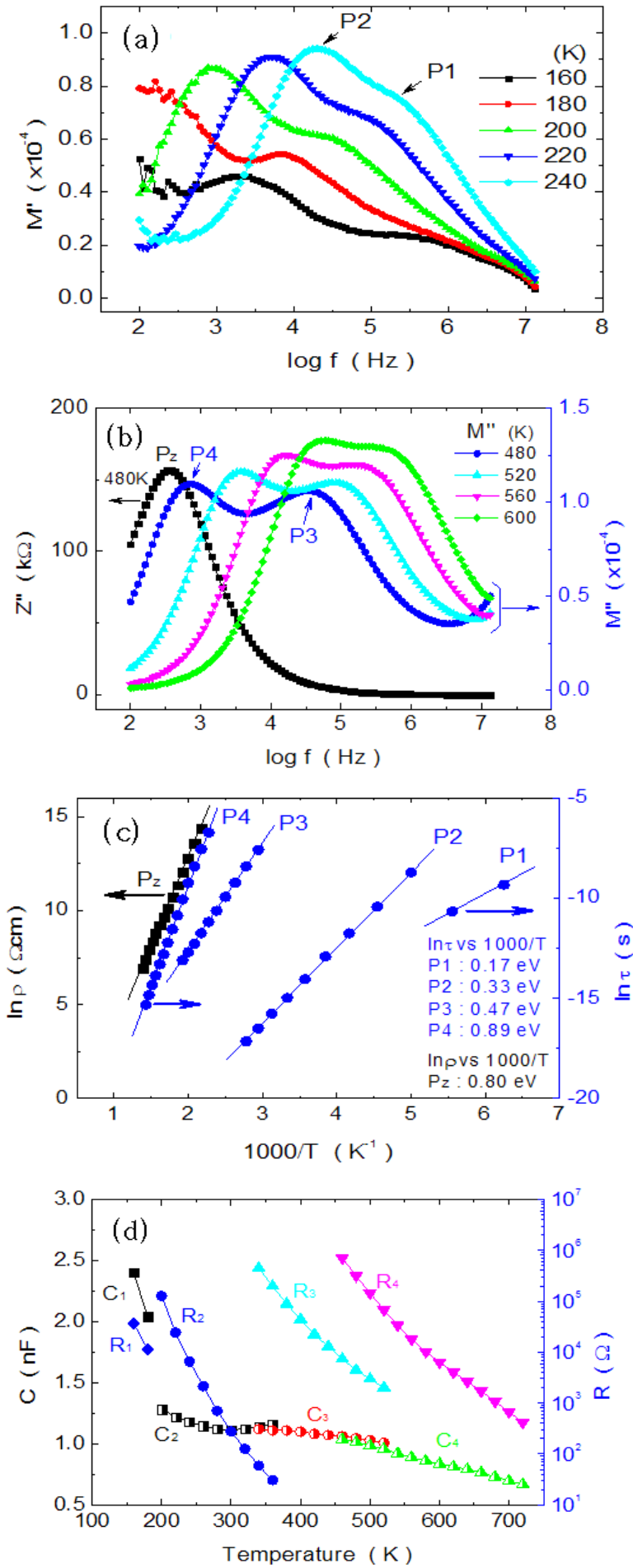

Fig. 5. Impedance and modulus spectroscopy of $\mathrm{ZBS}(\mathrm{MCo}) \quad(\mathrm{Sb} / \mathrm{Bi}=0.5)$ sintered at $1,300^{\circ} \mathrm{C}$. (a) $M^{\prime \prime}-\log f$ $(160 \sim 240 \mathrm{~K})$, (b) $Z^{\prime \prime}-$, $M^{\prime \prime}-\log f(480 \sim 600 \mathrm{~K})$, (c) $\ln \rho$ and $\ln \tau$ vs. $1,000 / T$ plot, (d) resistance $\left(R_{1 \sim 4}\right)$ and capacitance $\left(C_{1 \sim 4}\right)$ with temperature.
계의 $0.87 \mathrm{eV}$ 및 $0.75 \mathrm{eV}$ 와 거의 같지만, $\mathrm{ZBS}$ 의 1.02 $\mathrm{eV}, \mathrm{ZBSCo}$ 의 $0.93 \mathrm{eV}, \mathrm{ZBSN}$ 의 $1.3 \mathrm{eV}, \mathrm{ZBSCr}$ 의 1.1 $\mathrm{eV}, \mathrm{ZBCr}$ 의 $1.2 \mathrm{eV}$ 보다 낮게 나타났다 [8,18-22].

전체적으로 $\mathrm{ZBS}(\mathrm{MCo})$ 계의 입계는 두 종류로 구성 된 이중 입계이며, 입계 저항 $\left(R_{3,4}\right)$ 은 측정 온도가 높 아짐에 따라 지수적으로 감소하지만, 정전용량 $\left(C_{3,4}\right)$ 은 서로 거의 같은 값을 가지면서 온도에 대하여 소폭 감 소하는 경향을 가졌다. 이와 같은 현상은 입계 저항이 1,600 배 이상 차이가 나고, 정전용량이 $1.0 \mathrm{nF}$ 으로 거 의 같은 이중 입계를 가진 $\mathrm{Mn}$ 을 첨가한 $\mathrm{ZBSM}$ 계와 유사하다 [21]. 그러나 $\mathrm{Co}$ 를 첨가한 $\mathrm{ZBSCo}$ 계가 단일 입계 $\left(C_{g b} \sim 0.6 \mathrm{nF}\right)$ 를 갖는 것과는 차이가 난다 [18]. 따라서 $\mathrm{ZBS}$ 계에 $\mathrm{Mn}$ 과 $\mathrm{Co}$ 를 동시에 첨가할 경우, 입 계는 $\mathrm{Mn}$ 에 의해 주도적으로 제어됨을 확인하였다. 또 한 $\mathrm{ZnO}$ 바리스터에서 입계는 첨가하는 도펀트의 종류 에 따라 그 활성화 에너지와 저항 및 정전용량이 다양 하게 달라지는 것을 알 수 있다.

\section{4. 결 론}

$\mathrm{Sb} / \mathrm{Bi}$ 비를 달리한 $\mathrm{ZBS}$ 계에 $\mathrm{Mn}_{3} \mathrm{O}_{4}$ 와 $\mathrm{Co}_{3} \mathrm{O}_{4}$ 를 $1: 1$ 비율로 그 합이 $1 / 3 \mathrm{~mol} \%$ 첨가한 $\mathrm{ZBS}(\mathrm{MCo})$ 계 바리 스터의 소결 및 전기적 특성에 대하여 분석한 결과 다음과 같은 결론을 얻었다.

$\mathrm{ZBS}(\mathrm{MCo})$ 계의 소결과 전기적 특성은 $\mathrm{Sb} / \mathrm{Bi}$ 비에 의해 제어되었다. 상발달과 관련하여 $\mathrm{Sb} / \mathrm{Bi}$ 비에 따라 $\mathrm{Mn}$ 과 $\mathrm{Co}$ 의 역할이 달리 나타났다. $\mathrm{Sb} / \mathrm{Bi}=2.0$ 은 파이 로클로어와 $\mathrm{a}^{-}$스피넬의 생성으로 $900^{\circ} \mathrm{C}$ 까지 치밀화가 억제되었으며, $\mathrm{Sb} / \mathrm{Bi}=1.0$ 은 파이로클로어와 $\mathrm{a}$-스피넬 이 생성되지만 $\mathrm{Co}$ 보다 $\mathrm{Mn}$ 에 의해 파이로클로어의 분해 온도를 낮추는 효과가 나타났다. 한편 $\mathrm{Sb} / \mathrm{Bi}=0.5$ 는 스피넬 ( $\alpha$ 또는 $\beta$ )의 생성 자체를 없게 하는 $\mathrm{Co}$ 의 역할이 주도적으로 나타났다. 모든 계에서 파이로클 로어가 냉각 시 재생성되었으며, $\mathrm{Sb} / \mathrm{Bi} \geq 1.0$ 인 조성에 서 $\mathrm{a}$-스피넬의 $\mathrm{ZnO}$ 입성장 제어 효과에 의해 보다 균일한 미세구조를 형성하였다. $\mathrm{Mn}$ 과 $\mathrm{Co}$ 를 함께 첨 가함에 따라 바리스터 특성 (비선형 계수, $a=30 ~ 49$ ) 은 크게 개선되었고, 주된 결함으로 $Z n_{i}^{*}(0.17 \mathrm{eV})$ 와 $V_{o}^{*}(0.33 \mathrm{eV})$ 가 확인되었으며 이들의 정전용량은 측 정 온도에 따라 감소하는 경향을 나타냈다. 입계에서 는 $\mathrm{Mn}$ 의 역할이 주도적으로 나타났으며, 누설전류와 관련된 $\mathrm{ZnO} / \mathrm{Bi}_{2} \mathrm{O}_{3}(\mathrm{Mn}, \mathrm{Co}) / \mathrm{ZnO}\left(\mathrm{E}_{\mathrm{a}}=0.47 \mathrm{eV}\right)$ 계면과 바리스터 거동과 관련된 $\quad \mathrm{ZnO} / \mathrm{ZnO} \quad\left(\mathrm{E}_{\mathrm{a}}=0.80 \sim 0.89\right.$ 
$\mathrm{eV})$ 계면의 두 종류로 구성되었다. 각 입계의 저항은 약 70 배의 차이를 보이면서 온도에 대하여 지수적으 로 감소하였고, 정전용량은 거의 일정 $(0.7 \sim 1.1 \mathrm{nF})$ 하지만 온도에 대하여 소폭 감소하는 경향을 보였다.

\section{REFERENCES}

[1] D. R. Clarke, J. Am. Ceram. Soc., 82, 485 (1999).

[2] K. Eda, IEEE Elec. Insulation. Mag., 5, 28 (1989).

[3] R. Einzinger, Ann. Rev. Mater. Sci., 17, 299 (1987).

[4] F. Greuter and G. Blatter, Semicond. Sci. Technol., 5, 111 (1990).

[5] M. Inada and M. Matsuoka, Advances in Ceramics (American Ceramic Society, Columbus, 1983) p. 91.

[6] J. Kim, T. K. Kimura, and T. Yamaguchi, J. Am. Ceram. Soc., 72, 1390 (1989).

[7] Y. W. Hong and J. H. Kim, J. Kor. Ceram. Soc., 37, 651 (2000).

[8] Y. W. Hong, H. S. Shin, D. H. Yeo, J. H. Kim, and J. H. Kim, J. KIEEME, 21, 738 (2008).

[9] L. Karanović, D. Poleti, and D. Vasović, Mater. Lett., 18, 191 (1994).

[10] A. Mergen and W. E. Lee, J. Euro. Ceram. Soc., 17, 1049 (1997).
[11] Z. Branković, G. Branković, D. Poleti, and J. A. Varela, Ceram. Int., 27, 115 (2001).

[12] H. R. Philipp, Materials Science Research, Tailoring Multiphase and Composite Ceramics (eds. R. E. Tressler, G. L. Messing, C. G. Pantano, and R. E. Newnham) (Prenum Press, New York/London, 1987) p. 481.

[13] M. Andres-Verges and A. R. West, J. Electroceram., 1, 125 (1997).

[14] K. A. Abdullah, A. Bui, and A. Loubiere, J. Appl. Phys., 69, 4046 (1991).

[15] I. M. Hodge, M. D. Ingram, and A. R. West, J. Electroanal. Chem., 74, 125 (1976).

[16] E. Barsoukov and J. R. Macdonald, Impedance Spectroscopy (John Wiley \& Sons, New York, 2005) p. 1

[17] R. Gerhardt, J. Phys. Chem. Solids, 55, 1491 (1994).

[18] Y. W. Hong, H. S. Shin, D. H. Yeo, and J. H. Kim, J. KIEEME, 24, 969 (2011).

[19] Y. W. Hong, H. S. Shin, D. H. Yeo, J. H. Kim, and J. H. Kim, J. KIEEME, 22, 941 (2009).

[20] Y. W. Hong, H. S. Shin, D. H. Yeo, and J. H. Kim, J. KIEEME, 23, 942 (2010).

[21] Y. W. Hong and J. H. Kim, Ceram. Int., 30, 1307 (2004).

[22] Y. W Hong, H. S. Shin, D. H. Yeo, and J. H. Kim, J. KIEEME, 23, 368 (2010). 